\title{
Perforated esophageal intervention focus (PERF) study: a multi-center examination of contemporary treatment
}

\begin{abstract}
J. T. Ali, ${ }^{1}$ R. D. Rice, ${ }^{2}$ E. A. David, ${ }^{3}$ J. D. Spicer, ${ }^{4}$ J. J. Dubose, ${ }^{5}$ L. Bonavina, ${ }^{6}$ S. Siboni, ${ }^{7}$ T. A. O'Callaghan, ${ }^{8}$ X. Luo-Owen, ${ }^{8}$ S. Harrison, ${ }^{9}$ C. G. Ball, ${ }^{10}$ J. Bini, ${ }^{11}$ G. A. Vercruysse, ${ }^{12}$ D. Skarupa, ${ }^{13}$ C. C. Miller III, ${ }^{14}$ A. L. Estrera, ${ }^{14}$ K. G. Khaliil ${ }^{14}$

${ }^{1}$ The University of Texas at Austin, Austin, Texas, ${ }^{2}$ San Antonio Military Medical Center, San Antonio, ${ }^{3}$ Department of Surgery, University of California at Davis, Sacramento, ${ }^{4}$ McGill University, Montreal, Quebec, ${ }^{5}$ David Grant Medical Center, Travis AFB, ${ }^{6}$ Department of Surgery, University of Milan, Milan, Italy, ${ }^{7}$ Department of Surgery, University of Southern California, Los Angeles County, Los Angeles, ${ }^{8}$ Division of Trauma Services, Loma Linda University, Loma Linda, California, ${ }^{9}$ Department of Cardiothoracic Surgery, University of Mississippi, Jackson, Mississippi, ${ }^{10}$ Department of Surgery, University of Calgary Foothills Medical Center, Calgary, Alberta, Canada, ${ }^{11}$ Miami Valley Hospital, Department of Surgery, Dayton, Ohio, ${ }^{12}$ Department of Surgery, University of Arizona, Tucson, Arizona, ${ }^{13}$ Department of Surgery, University of Florida-Jacksonville, Jacksonville, Florida, USA, and ${ }^{14}$ Houston Medical Center, University of Texas, Houston, Texas
\end{abstract}

\begin{abstract}
SUMMARY. The treatment of esophageal perforation (EP) remains a significant clinical challenge. While a number of investigators have previously documented efficient approaches, these were mostly single-center experiences reported prior to the introduction of newer technologies: specifically endoluminal stents. This study was designed to document contemporary practice in the diagnosis and management of EP at multiple institutions around the world and includes early clinical outcomes. A five-year (2009-2013) multicenter retrospective review of management and outcomes for patients with thoracic or abdominal esophageal perforation was conducted. Demographics, etiology, diagnostic modalities, treatments, subsequent early outcomes as well as morbidity and mortality were captured and analyzed. During the study period, 199 patients from 10 centers in the United States, Canada, and Europe were identified. Mechanisms of perforation included Boerhaave syndrome $(60,30.1 \%)$, iatrogenic injury $(65,32.6 \%)$, and penetrating trauma $(25,12.6 \%)$. Perforation was isolated to the thoracic segment alone in $124(62.3 \%)$, with 62 $(31.2 \%)$ involving the thoracoabdominal esophagus. Mean perforation length was $2.5 \mathrm{~cm}$. Observation was selected as initial management in $65(32.7 \%)$, with only two failures. Direct operative intervention was initial management in 65 patients $(32.6 \%)$, while $29(14.6 \%)$ underwent esophageal stent coverage. Compared to operative intervention, esophageal stent patients were significantly more likely to be older $(61.3 \mathrm{vs} .48 .3$ years old, $P<0.001)$ and have sustained iatrogenic mechanisms of esophageal perforation (48.3\% vs.15.4\%). Secondary intervention requirement for patients with perforation was $33.7 \%$ overall (66). Complications included sepsis (56, 28.1\%), pneumonia (34, $17.1 \%)$ and multi-organ failure $(23,11.6 \%)$. Overall mortality was $15.1 \%(30)$. In contemporary practice, diagnostic and management approaches to esophageal perforation vary widely. Despite the introduction of endoluminal strategies, it continues to carry a high risk of mortality, morbidity, and need for secondary intervention. A concerted multi-institutional, prospectively collected database is ideal for further investigation.
\end{abstract}

$K E Y$ WORDS: drainage, endoscopy, esophageal perforation, esophagostomy, stents, wounds and injuries.

Address correspondence to: Jawad T. Ali, MD, 4223 J St, Unit 3, Sacramento, CA 95819, USA. Email: jawada@gmail.com This paper was presented at the 95th Annual Meeting of the American Association of Thoracic Surgery Moderated Poster Session.

All research funding was appropriated through internal sources at each specific site for completion of this study.

Specific author contributions: This work represents the original efforts of the investigators. All listed authors contributed to study

\section{INTRODUCTION}

Esophageal perforation (EP) (Fig. 1) remains a significant clinical challenge associated with considerable morbidity and a reported mortality approaching

\footnotetext{
design, data collection, data interpretation, and manuscript development.

Conflicts of interest: The authors declare that they have no conflict
} of interest. 


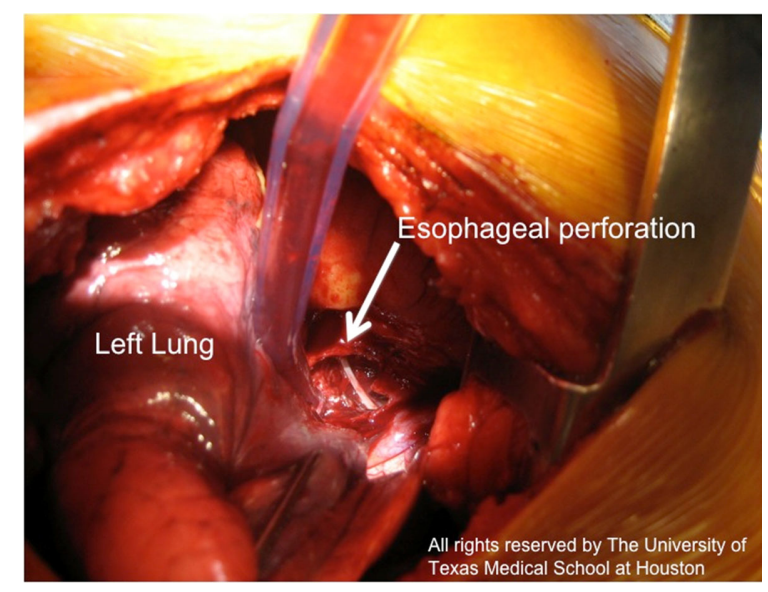

Fig. 1 Intraoperative photo demonstrating a benign esophageal perforation of a duck bone in the lower third of the esophagus addressed via a left thoracotomy.

$25 \% .^{1-21}$ The causes of perforation are myriadincluding iatrogenic injury, trauma, Boerhaave's syndrome, and as a complication of various preexisting esophageal conditions. ${ }^{1-5,7,12,19}$ Traditional treatment algorithms have relied upon the rapid delineation of the offending lesion's location using endoscopy or radiographic studies, and determination of time from rupture to guide subsequent therapy. ${ }^{3-6,14}$ Time from diagnosis, physiologic condition at presentation, performance status of the patient, and efficacy of the chosen initial intervention to treat the perforation have all been documented to be associated with patient outcome. ${ }^{1}$

There have been a number of reported experiences in the diagnosis and management of esophageal perforation. ${ }^{1-4,6,8,10,13-21}$ Many of these previous reports, however, have documented single-center experience over lengthy intervals during which practice may have evolved. Interval advances in diagnostic and therapeutic approaches, including improved diagnostic capabilities and the emergence of endoscopic technologies, have contributed to an evolution in modern practice patterns. For example, it has been reported that the traditional utilization of fluoroscopic studies has been supplanted by computed tomography in some clinical settings. ${ }^{14,18}$ Modern treatment paradigms at select centers also include the consideration for endoscopic intervention adjuncts in clinical scenarios where drainage/diversion or open surgical procedures were previously the mainstay of initial management. ${ }^{10}$

This study was conducted and designed to capture contemporary diagnostic approaches, management strategies, and outcomes of thoracic and abdominal esophageal perforation in a multi-center fashion. It is our hope that reporting our collaborative experience will assist in defining modern practice patterns and highlight opportunities for additional clinical study designed to define optimal management of esophageal perforation.

\section{MATERIALS AND METHODS}

After individual Institutional Review Board (IRB) approval, 10 different sites in the North America and Europe collaborated to contribute data to this examination. Centers were selected based upon prior research relationships that expressed interest in participating in the retrospective review. All centers are tertiary care facilities with a full complement of general surgery, thoracic surgery, and advanced endoscopic capabilities.

Data were collected over a 5-year period from January 2009 to December 2013. Patients were deemed eligible for inclusion if they were over 18 years of age and sustained perforation of the intrathoracic or abdominal esophagus whether from traumatic, iatrogenic, or benign etiology. Esophageal perforations were identified initially by query of individual electronic medical records for ICD-9 code 530.4, ICD-10CM K22.3 or free text search of the medical record for 'esophageal perforation.' Individual medical chart and imaging review were utilized to confirm these diagnoses prior to inclusion. For the purpose of our examination, patients with documented esophageal carcinoma or leakage after a recent esophageal resection were excluded from examination. Once data collection was completed, all data were appropriately deidentified and collated into a centralized collection database at the primary author's institution.

\section{Definitions utilized}

Esophageal perforation was defined as a perforation of the esophagus from the thoracic inlet to the esophagogastric junction. Patients were grouped according to their initial therapy: (1) Patients receiving no invasive therapy were placed into the observational arm; (2) Thoracostomy tube drainage only, (3) Diversion/gastric drainage. (4) Open operative intervention specifically requiring a thoracotomy, (5) Esophageal stent placement, or (6) hybrid endoluminal and open approach. Treatment failure was a priori defined as patients requiring secondary intervention, either within the same treatment category or resulting in crossing over to an alternate treatment category. These included continuing esophageal leak, treatment of persistent fluid collection, and esophageal stent exchange or repositioning.

Early mortality was defined as death during initial hospitalization. End-stage renal disease (ESRD) was defined as patients that required initiation of dialysis during hospitalization. Acute renal failure was determined by RIFLE criteria using admission laboratory 
values. ${ }^{21}$ Multiorgan failure was defined as significant dysfunction of 2 or more organ systems. Chronic obstructive pulmonary disease (COPD) and gastroesophageal reflux disease (GERD) were tabulated from the medical history. Sepsis was defined as meeting systemic inflammatory response (SIRS) criteria with positive cultured source of bacteremia. ${ }^{22,23}$

\section{Statistical analysis}

Data were analyzed using SAS version 9.3 (SAS Institute, Inc., Cary, NC). Normally distributed continuous variables were compared using Student's t-test and skewed variables such as time from symptom onset to treatment were compared using the Wilcoxon Rank-Sum test. All continuous variables were analyzed for skewness, with those demonstrating a normal distribution reported using standard deviations and those with distributions that were not normal reported using interquartile range and nonparametric testing (Mann-Whitney) to examine differences between populations. Chi-squared tests were used for contingency table analyses unless the expected value assumptions were not met, in which case Fisher's exact test was used.

\section{RESULTS}

\section{Diagnosis}

A total of 199 patients with esophageal perforation of the thoracic or thoracoabdominal segments were identified. The mean number of patients identified at each institution was 10 [IQR: 7-31]. The mean age of patients was 58.3 [IQR: 39-70] years (Table 1). The majority of perforations reported were from Boerhaave's syndrome $(30.1 \%)$ and iatrogenic etiologies $(32.6 \%)$. Patients presented with chest/back pain $(55.8 \%)$ and tachycardia $(33.8 \%)$ as the most common clinical findings. Laboratory abnormalities, including elevated lactate and leukocytosis were common (Table 1). Computed tomography of the chest was identified as the most commonly utilized imaging modality when there was a concern for EP $(74.1 \%)$, with pleural effusion proving the most commonly associated imaging finding (54.3\%). The majority of patients had a perforation of the thoracic esophagus $(62.3 \%)$ (Table 1$)$.

\section{Initial esophageal interventions}

Initial therapies employed in the treatment of EP are outlined in Figure 2. Sixty-five patients $(32.6 \%)$ required no initial invasive intervention and were managed with antibiotic therapy and monitoring. Isolated tube thoracostomy drainage was employed in 29
Table 1 Demographics, mechanism, presentation, imaging, and initial treatment of esophageal perforation (EP) patients $(N=199)$

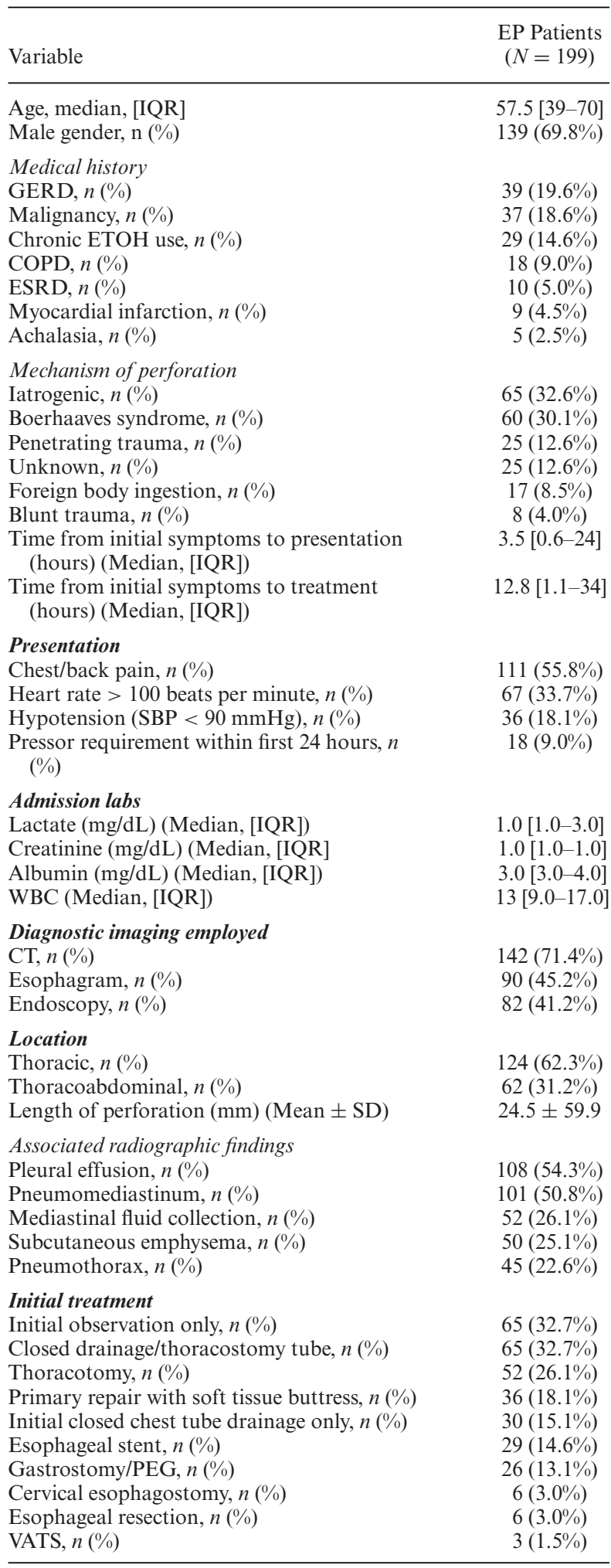

Categorical data shown as number $(\%)$ and continuous data as mean + standard deviation.

COPD, chronic obstructive pulmonary disease; CT, computed tomography; ESRD, end-stage renal disease; ETOH, ethanol; GERD, gastroesophgaeal reflux disease; PEG, percutaneous endoscopic gastrostomy; SBP, systolic blood pressure; SD, standard deviation; WBC, white blood cell count; VATS, videoscopicassisted thorascopic surgery. 


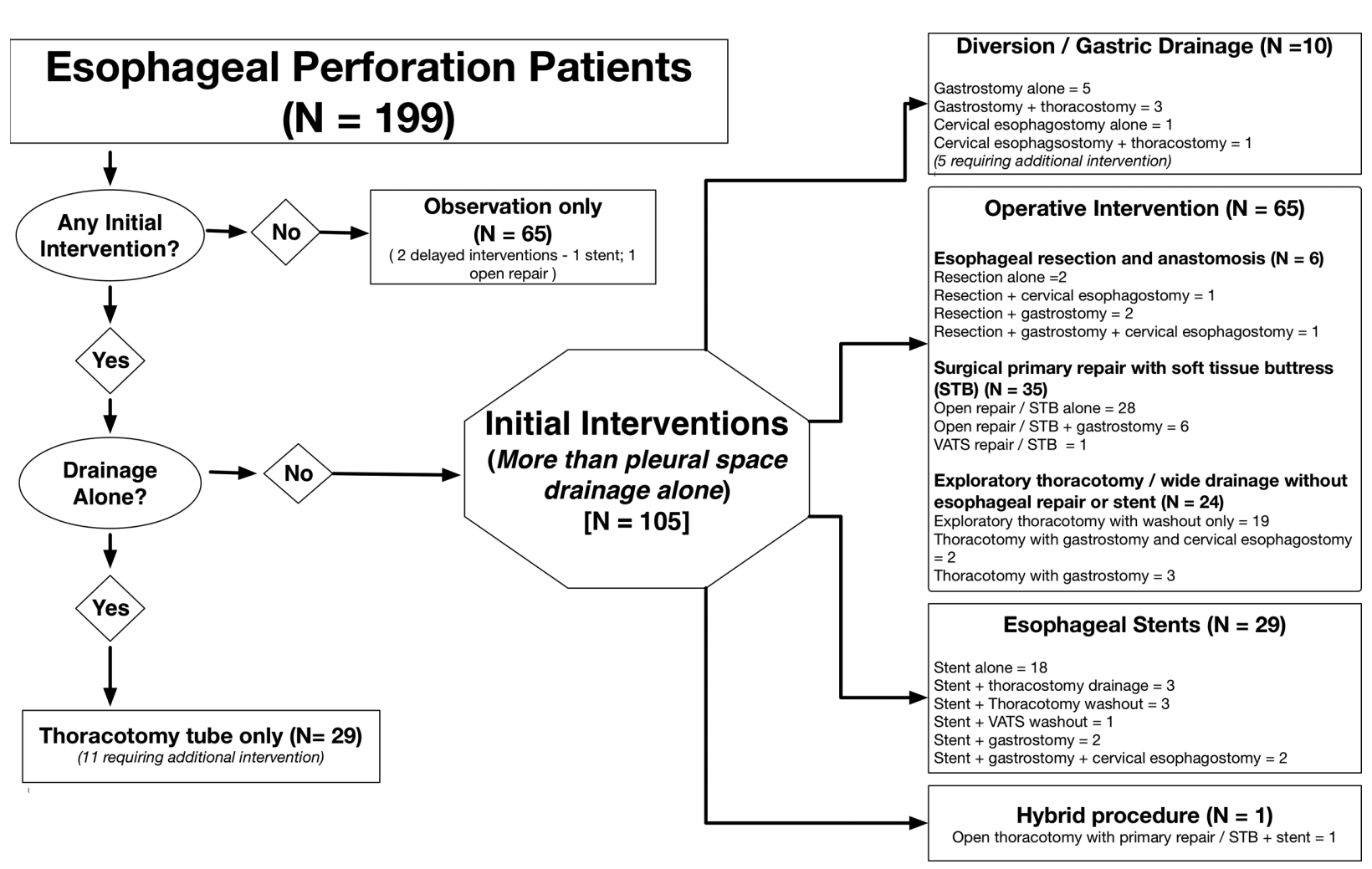

Fig. 2 Flow-sheet outline of strategies employed for initial management of patients presenting with esophageal perforation.

patients $(14.6 \%)$. Among those requiring more aggressive initial intervention, sixty-five patients $(32.6 \%)$ underwent an open thoracotomy and 10 patients $(5 \%)$ underwent enteric diversion/drainage/bypass via cervical diversion, gastric drainage, or a combination of the two. Endoluminal stent coverage was utilized as initial treatment modality in $29(14.5 \%)$, and a hybrid endoluminal/open thoracotomy was employed for one patient.

\section{Secondary esophageal interventions}

Secondary esophageal interventions were required in 67 patients (33\%) (Table 2). The most common intervention was additional closed suction drainage for persistent pleural effusion or recurrent leak (19.1\%).

Among the 65 patients who underwent only observation, there were two treatment failures (3\%) (Fig. 2). One of these patients underwent thoracotomy with delayed primary repair, including a soft-tissue buttress and chest tube drainage for a persistent pleural effusion. The other underwent esophageal stent placement with tube thoracostomy for delayed presentation of an esophageal leak.

Among the 29 patients who were treated with isolated chest tube therapy, 11 required further intervention. A variety of secondary interventions were employed for these patients, including additional chest tube drainage (7), gastrostomy tube placement (1), thoracotomy (1), esophageal stent alone (1), and
Table 2 Analysis of secondary interventions and indications for further therapy $(N=199)$

\begin{tabular}{lc}
\hline & EP patients \\
Variable & $N=199(\%)$ \\
\hline Any secondary intervention required, $n(\%)$ & $67(33.7 \%)$ \\
Secondary interventions & \\
Minor & \\
Closed drainage/thoracostomy tube, $\mathrm{n}(\%)$ & $38(19.1 \%)$ \\
Major & \\
Thoracotomy, $n(\%)$ & $26(13.1 \%)$ \\
Gastrostomy/PEG, $n(\%)$ & $25(12.6 \%)$ \\
Esophageal stent, $n(\%)$ & $11(5.5 \%)$ \\
Primary repair with soft tissue buttress, $n(\%)$ & $10(5.0 \%)$ \\
Cervical esophagostomy, $n(\%)$ & $9(4.5 \%)$ \\
Esophageal resection, $n(\%)$ & $7(3.5 \%)$ \\
VATS, $n(\%)$ & $2(1.0 \%)$ \\
Indications for secondary intervention & \\
Pleural effusion, $n(\%)$ & $28(14.1 \%)$ \\
Recurrent leak, $n(\%)$ & $26(13.1 \%)$ \\
Empyema, $n(\%)$ & $17(8.5 \%)$ \\
Sepsis, $n(\%)$ & $15(7.5 \%)$ \\
Mediastinal infection, $n(\%)$ & $11(5.5 \%)$ \\
Stent migration, $n(\%)$ & $6(3.0 \%)$ \\
\hline
\end{tabular}

Categorical data shown as number (\%) and continuous data as mean \pm standard deviation.

PEG, percutaneous endoscopic gastrostomy; VATS, videoscopicassisted thorascopic surgery.

esophageal stent combined with thoracostomy tube placement (1).

Among the ten patients that had an initial diversion/gastric drainage, $50 \%$ underwent a secondary intervention in the form of thoracostomy tube (Fig. 2). 
Table 3 In-hospital morbidity, length of stay, and mortality

\begin{tabular}{lc}
\hline Variable & EP patients \\
$N=199(\%)$ \\
\hline Hospital complications & \\
Sepsis, $n(\%)$ & $56(28.1 \%)$ \\
Bacteremia, $n(\%)$ & $35(17.6 \%)$ \\
Pneumonia, $n(\%)$ & $34(17.1 \%)$ \\
Multiorgan failure, $n(\%)$ & $23(11.6 \%)$ \\
Acute renal failure, $n(\%)$ & $22(11.0 \%)$ \\
Empyema, $n(\%)$ & $20(10.0 \%)$ \\
Myocardial infarction, $n(\%)$ & $1(0.5 \%)$ \\
Stent erosion, $n(\%)$ & $1(0.5 \%)$ \\
Hospital course & \\
ICU LOS (days) (median, IQR) & $4.0,15$ \\
Hospital LOS (days) (median, IQR) & $19.0,19$ \\
Ventilator days (Mean \pm SD) & $1.0,5$ \\
Death, $n(\%)$ & $30(15.1 \%)$ \\
\hline
\end{tabular}

ICU, intensive care unit; IQR, interquartile range; LOS, length of stay; SD, standard deviation.

The secondary intervention requirements for patients undergoing either open operative intervention or esophageal stent are shown in Table 2. Operative intervention required secondary adjuncts in $55.4 \%$, while stenting required additional procedures in $44.8 \%$. The most common secondary requirement in both groups was additional thoracostomy tube drainage (Table 2). The most common indications for secondary intervention after open repair were recurrent leak $(16.9 \%)$, empyema $(16.9 \%)$, and pleural effusion (16.9\%). After stenting, the most common indications for additional procedure were pleural effusion $(27.6 \%)$ and recurrent leak (24.1\%).

\section{Postoperative characteristics}

The postoperative findings are tabulated in Table 3. The median length of stay was 19.0 days (Interquartile range $(I Q R)=19)$ with patients requiring a median intensive care unit stay of 4.0 days. The most common in-hospital complications were sepsis $(28.1 \%)$, culture positive bacteremia (17.6\%), and pneumonia (17.1\%). The overall mortality rate seen for the series was $15.1 \%$ $(n=30)$. The median time spent on the ventilator for associated respiratory failure was 1 day $(\mathrm{IQR}=5)$.

\section{Univariate comparison of primary operative interventions to esophageal stent employment}

Patients who underwent operative intervention with a thoracotomy compared to those who were managed with an esophageal stent were significantly younger $(P<0.001)$ (Table 4$)$. However, there was not a significant difference in these groups' comorbidities. Esophageal stents were used significantly more frequently in patients presenting with an iatrogenic perforation $(P<0.001)$ and thoracotomies were employed most often for penetrating trauma victims $(P<0.011)$. There was no significant difference in presentation vital sign values, symptoms, or admission laboratory values between open repair patients and those treated with endoluminal stents. The patients who had esophageal stents utilized were more commonly imaged with computed tomography scans $(P<0.015)$ (Table 4$)$. There was no difference in the locations of the perforation in both groups. There was no statistical significance seen in the rate of required secondary interventions between the thoracotomy and stent patients.

Both patient types most often required additional tube thoracostomy drainage. Secondary interventions were most commonly required for pleural effusions and persistent leak with no significant differences elucidated (Table 5). Sepsis, pneumonia, bacteremia, and empyema were common in both cohorts without significant difference (Table 5). There was no significant difference in ICU length of stay, hospital stay, or mortality in the groups undergoing operative intervention or stent deployment (Table 5).

\section{DISCUSSION}

The results of our international multicenter retrospective study provide a picture of current practice in the management of the perforated esophagus. These results reflect those of other studies stating that esophageal perforation is a rare entity with high rates of morbidity and mortality. As with any disruptive technology, the introduction of esophageal stenting has dramatically changed the potential clinical decision tree for the management of esophageal perforation. $^{24}$

Guidelines from the Western Trauma Association in 2015 now recommend endoscopic treatment for the stable trauma patient with a small thoracic esophageal perforation due to trauma either by stenting or clipping. ${ }^{25}$ In addition, Ben-David et al.'s group from the University of Florida - Gainesville have shown that low mortality rates $(1.3 \%)$ are possible with a protocol centered on endoscopic stenting techniques in the right setting. ${ }^{26}$ Furthermore, a large retrospective series from England by Markar et al. focusing on spontaneous PE also demonstrated decreasing surgical intervention and increasing use of endoscopy and supportive care over the study period of 2001 to $2012 .^{27}$

The goal of this study is primarily to provide a contemporary snapshot of management strategies being employed in the care of these complex patients. Secondarily, we wished to determine the impact of the various treatment strategies identified on short-term, perioperative outcomes. This work represents a large, multinational study and provides a broad perspective on how esophageal perforation is being managed in a wide variety of settings around the world. 
Table 4 Univariate analysis of characteristics, comorbid conditions, and presentation in patients with operative intervention versus esophageal stent placement

\begin{tabular}{|c|c|c|c|}
\hline Variable & $\begin{array}{l}\text { Operative intervention } \\
\qquad N=65(\%)\end{array}$ & $\begin{array}{c}\text { Stent } \\
N=29(\%)\end{array}$ & $P$-value \\
\hline \multicolumn{4}{|l|}{ Patient characteristics } \\
\hline Age & $48.3 \pm 20.4$ & $61.3 \pm 14.4$ & $<0.001$ \\
\hline Male gender & $47(72.3 \%)$ & $19(65.5 \%)$ & 0.506 \\
\hline \multicolumn{4}{|l|}{ Comorbid conditions } \\
\hline ESRD, $n(\%)$ & $4(6.2 \%)$ & $2(6.9 \%)$ & 1.000 \\
\hline COPD, $n(\%)$ & $5(7.7 \%)$ & $5(17.2 \%)$ & 0.275 \\
\hline Myocardial infarction, $n(\%)$ & $2(3.1 \%)$ & $2(6.9 \%)$ & 0.585 \\
\hline Chronic ETOH use, $n(\%)$ & $8(12.3 \%)$ & $7(24.1 \%)$ & 0.221 \\
\hline GERD, $n(\%)$ & $9(13.8 \%)$ & $7(24.1 \%)$ & 0.224 \\
\hline Malignancy, $n(\%)$ & $7(10.8 \%)$ & $10(34.5 \%)$ & 0.006 \\
\hline \multicolumn{4}{|l|}{ Mechanism of perforation } \\
\hline Boerhaaves syndrome, $n(\%)$ & $22(33.8 \%)$ & $7(24.1 \%)$ & 0.347 \\
\hline Iatrogenic, $n(\%)$ & $10(15.4 \%)$ & $14(48.3 \%)$ & 0.001 \\
\hline Foreign body ingestion, $n(\%)$ & $8(12.3 \%)$ & $0(0.0 \%)$ & 0.055 \\
\hline Blunt trauma, $n(\%)$ & $1(1.5 \%)$ & $0(0.0 \%)$ & 1.000 \\
\hline Penetrating trauma, $n(\%)$ & $17(26.2 \%)$ & $1(3.4 \%)$ & 0.010 \\
\hline Unknown, $n(\%)$ & $7(10.8 \%)$ & $7(24.3 \%)$ & 0.689 \\
\hline $\begin{array}{l}\text { Time from initial symptoms to presentation } \\
\text { (hours) (median [IQR]) }\end{array}$ & $8[3-24]$ & $1.41[0.3-9.5]$ & 0.231 \\
\hline $\begin{array}{l}\text { Time from initial symptoms to treatment } \\
\text { (hours) (Median [IQR]) }\end{array}$ & $35[8.25-113.33]$ & $12.3[3.38-26.66]$ & 0.771 \\
\hline \multicolumn{4}{|l|}{ Presentation } \\
\hline Hypotension $(\mathrm{SBP}<90 \mathrm{mmHg})$ & $14(21.5 \%)$ & $5(17.2 \%)$ & 0.632 \\
\hline Pressor requirement within first 24 hours & $7(10.8 \%)$ & $2(10.5 \%)$ & 1.000 \\
\hline Chest/back pain & $38(58.5 \%)$ & $15(51.7 \%)$ & 0.543 \\
\hline Heart rate $>100$ beats per minute & $1(1.5 \%)$ & $0(0.0 \%)$ & 0.500 \\
\hline \multicolumn{4}{|l|}{ Admission labs } \\
\hline Lactate $(\mathrm{mg} / \mathrm{dL})($ Mean $\pm \mathrm{SD})$ & $5.8 \pm 8.7$ & $1.7 \pm 2.5$ & 0.062 \\
\hline Creatinine (mg/dL) (Mean \pm SD) & $1.3 \pm 1.3$ & $1.1 \pm 0.5$ & 0.409 \\
\hline Albumin $(\mathrm{mg} / \mathrm{dL})($ Mean $\pm \mathrm{SD})$ & $2.9 \pm 0.9$ & $2.9 \pm 1.0$ & 0.930 \\
\hline $\mathrm{WBC}(\mathrm{Mean} \pm \mathrm{SD})$ & $12.9 \pm 6.0$ & $15.6 \pm 7.1$ & 0.064 \\
\hline \multicolumn{4}{|l|}{ Diagnostic imaging employed } \\
\hline $\mathrm{CT}, n(\%)$ & $37(56.9 \%)$ & $24(82.8 \%)$ & 0.015 \\
\hline Esophagram, $n(\%)$ & $29(44.6 \%)$ & $10(34.5 \%)$ & 0.357 \\
\hline Endoscopy, $n(\%)$ & $21(32.3 \%)$ & $21(72.4 \%)$ & $<0.001$ \\
\hline
\end{tabular}

Categorical data shown as number ( $\%$ ) and continuous data as mean \pm standard deviation.

COPD, chronic obstructive pulmonary disease; CT, computed tomography; ESRD, end-stage renal disease; ETOH, ethanol; GERD, gastroesophageal reflux disease; HTN, hypertension; SD, standard deviation; WBC, White Blood Cell Count.

Depending on institutional practices and presentation, patients with esophageal perforation may be treated by a number of specialists with varying degrees of expertise and technical abilities. ${ }^{3,4,6,10}$ Given the rarity and unpredictability of these events, it is difficult for any one program to gain a large volume of experience with such patients. A recent large, multiinstitutional study quoted an average of 3.9 cases per year per institution. ${ }^{3}$ Because of these factors, combined with the introduction of new endoscopic technologies, there was a need to address the current stateof-the-art from a clinical perspective through a large, multi-institutional retrospective review. In doing so, we aimed to identify treatment paradigms and key factors on which to focus as we move toward building a prospective registry on the management of esophageal perforation.

Our results suggest that four primary treatment paradigms can be identified: (1) Observation; (2) Varying degrees of diversion and drainage;
(3) Up-front esophageal stenting with or without additional drainage procedures; and (4) Up-front thoracotomy, followed by repair or wide drainage. Naturally, the choice of approach depends largely on presenting signs and symptoms as well as the preference of the treating provider. However, it is difficult in this retrospective review to identify the chosen rationale for each approach. Furthermore, we have collected a very diverse group of patients who developed esophageal perforation based on a wide range of inciting events. These factors make direct comparison of the different treatment strategies very difficult and clearly constitute one of the major limitations of this study. However, by including such a wide variety of patients, we have been able to identify findings from which to move forward.

EP continues to carry a high risk of mortality overall, as well as a need for secondary intervention with one-third of all patients requiring some form of additional procedure. ${ }^{4,20}$ This study identified a 
Table 5 Univariate analysis of secondary esophageal interventions and postoperative outcomes in patients with operative interventions versus esophageal stent placement

\begin{tabular}{|c|c|c|c|}
\hline Variable & $\begin{array}{c}\text { Operative intervention } \\
\qquad N=65(\%)\end{array}$ & $\begin{array}{c}\text { Stent } \\
N=30(\%)\end{array}$ & $P$-value \\
\hline Any secondary intervention required, $n(\%)$ & $36(55.4 \%)$ & $13(44.8 \%)$ & 0.344 \\
\hline $\begin{array}{l}\text { Secondary interventions } \\
\text { Closed drainage/thoracostomy tube, } n(\%) \\
\text { Thoracotomy, } n(\%) \\
\text { VATS, } n(\%) \\
\text { Cervical esophagostomy, } n(\%) \\
\text { Esophageal resection, } n(\%) \\
\text { Primary repair with soft tissue buttress, } n(\%) \\
\text { Gastrostomy/PEG, } n(\%) \\
\text { Esophageal stent, } n(\%)\end{array}$ & $\begin{aligned} & 18(27.7 \%) \\
& 17(26.2 \%) \\
& 0(0.0 \%) \\
& 3(4.6 \%) \\
& 3(4.6 \%) \\
& 6(9.2 \%) \\
& 18(27.7 \%) \\
& 2(3.1 \%)\end{aligned}$ & $\begin{array}{l}8(27.6 \%) \\
5(17.2 \%) \\
2(6.9 \%) \\
3(10.3 \%) \\
2(6.9 \%) \\
3(10.3 \%) \\
4(13.8 \%) \\
5(17.2 \%)\end{array}$ & $\begin{array}{l}0.992 \\
0.346 \\
0.093 \\
0.368 \\
0.642 \\
1.000 \\
0.142 \\
0.027\end{array}$ \\
\hline $\begin{array}{l}\text { Indications for secondary intervention } \\
\text { Recurrent leak, } n(\%) \\
\text { Sepsis, } n(\%) \\
\text { Empyema, } n(\%) \\
\text { Pleural effusion, } n(\%) \\
\text { Mediastinal infection, } n(\%) \\
\text { Stent migration, } n(\%)\end{array}$ & $\begin{array}{l}11(16.9 \%) \\
9(13.8 \%) \\
11(16.9 \%) \\
11(16.9 \%) \\
5(7.7 \%) \\
0(0.0 \%)\end{array}$ & $\begin{array}{l}7(24.1 \%) \\
4(13.8 \%) \\
5(17.2 \%) \\
8(27.6 \%) \\
4(13.8 \%) \\
5(17.2 \%)\end{array}$ & $\begin{array}{l}0.412 \\
1.000 \\
1.000 \\
0.234 \\
0.451 \\
0.002\end{array}$ \\
\hline $\begin{array}{l}\text { Hospital complications } \\
\text { Bacteremia, } n(\%) \\
\text { Sepsis, } n(\%) \\
\text { Acute renal failure, } n(\%) \\
\text { Multiorgan failure, } n(\%) \\
\text { Myocardial infarction, } n(\%) \\
\text { Pneumonia, } n(\%) \\
\text { Empyema, } n(\%) \\
\text { Stent erosion, } \mathrm{n}(\%)\end{array}$ & $\begin{aligned} & 14(21.5 \%) \\
& 21(32.3 \%) \\
& 5(7.7 \%) \\
& 5(7.7 \%) \\
& 0(0.0 \%) \\
& 13(20.0 \%) \\
& 13(20.0 \%) \\
& 0(0.0 \%)\end{aligned}$ & $\begin{array}{l}8(27.6 \%) \\
11(37.9 \%) \\
2(6.9 \%) \\
5(17.2 \%) \\
0(0.0 \%) \\
9(31.0 \%) \\
6(20.7 \%) \\
0(0.0 \%)\end{array}$ & $\begin{array}{l}0.522 \\
0.595 \\
1.000 \\
0.275 \\
1.000 \\
0.243 \\
0.939 \\
1.000\end{array}$ \\
\hline $\begin{array}{l}\text { Hospital course } \\
\text { ICU LOS (days) (Mean } \pm \mathrm{SD}) \\
\text { Hospital LOS (days) }(\mathrm{Mean} \pm \mathrm{SD}) \\
\text { Ventilator days (Mean } \pm \mathrm{SD}) \\
\text { Death, } n(\%)\end{array}$ & $\begin{array}{c}13.8 \pm 17.5 \\
27.1 \pm 22.5 \\
9.1 \pm 14.8 \\
8(12.3 \%)\end{array}$ & $\begin{array}{c}12.0 \pm 12.2 \\
33.0 \pm 22.9 \\
5.2 \pm 9.9 \\
5(17.2 \%)\end{array}$ & $\begin{array}{l}0.636 \\
0.249 \\
0.204 \\
0.531\end{array}$ \\
\hline
\end{tabular}

Categorical data shown as number (\%) and continuous data as mean \pm standard deviation.

PEG, percutaneous endoscopic gastrostomy; VATS, video-assisted thoracoscopic surgery.

$15.1 \%$ mortality risk for the entire cohort, and this has been corroborated by similar large studies performed in recent years. $3,6,11,13,15,19,20$ Although esophageal stents may have allowed for minimally invasive management of certain patients, they have not led to a dramatic improvement in mortality from this condition as compared to data that predates the era of endoscopic therapies. ${ }^{1,20}$ In this report, despite patients in the stenting cohort being older $(P<0.001)$, outcomesin terms of hospital complications, ICU length of stay, ventilator days, hospital length of stay, and death were no different from those patients that underwent upfront thoracotomy (Table 4) Clearly, prospective evaluation of these two treatment strategies is required to resolve questions regarding the ideal indications for stent versus up-front thoracotomy and attempted repair.

It is important to note that preoperative factors that predict the likelihood that a repair will be feasible are lacking. It is critical to address the underlying pathology when formulating a treatment strategy such as performing a myotomy for a patient with achalasia. Additionally, we could not capture intent from our retrospective database so certain secondary interventions may have been planned rather than true treatment failures. Certainly, time from initial symptoms to presentation is a well-documented concept. However, in reality, the true extent of esophageal damage is often only identified at thoracotomy, where an intraoperative decision to repair or drain is made. ${ }^{1,4}$ Arguably, those patients with very short delays from initial symptoms and minimal mediastinal/pleural contamination may be those that are destined to the best outcomes, irrespective of the treatment strategy. The need to delineate the potential benefits of minimally invasive strategies based upon time from initial symptoms and other variables is a key rationale for a prospective registry.

Another interesting finding of our work and those of other groups is that the use of esophageal stenting does not appear to be associated with decreased secondary intervention rate. ${ }^{10,20}$ Although our stent migration rate was lower than previously reported series, it was not an uncommon event, occurring in $17.2 \%$ of our stented population..$^{20}$ Furthermore, the usage of stents did not obviate the need for operative drainage or, in some cases, even esophageal diversion. Perhaps with further improvements in the technology 
the migration rate, and hence the re-intervention rate, will ultimately decrease.

It will also be important to track outcomes beyond the initial hospitalization for these patients. In particular, patients who are managed with esophageal diversion are likely to require major reconstructive surgery after discharge. Not only do such approaches encroach tremendously on quality of life, but the morbidity and potential mortality of subsequent operations to restore digestive continuity must be assessed to gain a broader understanding of the treatments we offer this group of patients. We suggest that a multinational, collaborative group focused on the management of esophageal perforation is needed to track management strategies and outcomes after esophageal perforation in a prospective fashion. Such a collaborative venture should aspire to better delineate the optimal selection of specific management paradigms based on history, presentation, and imaging.

\section{CONCLUSIONS}

In conclusion, despite the inherent bias of a retrospective study, it is clear that the diagnostic and management approaches to EP continue to vary. Observation appears safe for select patients. Additionally, esophageal stenting does not appear to be associated with a decreased secondary intervention rate. Finally, despite a variety of available treatment adjuncts for those requiring intervention, EP persists in carrying a high risk of mortality. The heterogeneity in management strategies and paucity of multi-institutional data on the topic suggests that a collaborative, prospectively collected database is needed for the effective development of optimal guideline-based management strategies for EP.

\section{References}

1 White R K, Morris D M. Diagnosis and management of esophageal perforations. Am Surg 1992; 58: 112-9.

2 Nirula R. Esophageal perforation. Surg Clin North Am 2014; 94: 35-41.

3 Biancari F, D'Andrea V, Di Marco C et al. Current treatment and outcome of esophageal perforations in adults: systematic review and meta-analysis of 75 studies. World J Surg 2013; 37: 1051-9.

4 Brinster C J, Singhai S, Lee L, Marshall M B, Kaiser L R, Kucharczuk J C. Evolving options in the management of esophageal perforation. Ann Thorac Surg 2004; 77: 1475-83.

5 Connelly C L, Lamb P J, Paterson-Brown S. Outcomes following Boerhaave's syndrome. Ann R Coll Surg Engl 2013; 95: 557-60.

6 Biancari F, Saarnio J, Mennander A et al. Outcome of patients with esophageal perforations: a multicenter study. World J Surg 2014; 38: 902-9.

7 Kroepil F, Schauer M, Raffel A M, Kropoil P, Eisenberger C F, Knoefel W T. Treatment of early and delayed esophageal perforation. Indian J Surg 2013; 75: 469-72.
8 Heits N, Stapel L, Reichart B et al. Endoscopic endoluminal vacuum therapy in esophageal perforation. Ann Thorac Surg 2014; 97: 1029-35.

9 Kunkala M R, Deschamps C. Delayed esophageal diverticulum formation after stent-based treatment of perforation. J Thorac Cardiovasc Surg 2014; 147: e5-8.

10 El Hajj I I, Imperiale T F, Rex D K et al. Treatment of esophageal leaks, fistulae and perforations with temporary stents: evaluation of efficacy, adverse events, and factors associated with successful outcomes. Gastrointest Endosc 2014; 79 : 589-98.

11 Hashimoto C N, Cataneo C, Eldib R et al. Efficacy of surgical versus conservative treatment of esophageal perforation: a systematic review of case series studies. Acta Cir Bras 2013; 28: 26671 .

12 Jiang J, Yu T, Zhang Y F, Li J Y, Yang L. Treatment of cervical esophageal perforation caused by foreign bodies. Dis Esophagus 2012; $25: 590-4$

13 Kuppusamy M K, Hubka M, Felisky C D et al. Evolving management strategies in esophageal perforation: surgeons using nonoperative techniques to improve outcomes. J Am Coll Surg 2011;213: 164-72.

14 Ben-David K, Lopes J, Hochwald S et al. Minimally invasive treatment of esophageal perforation using a multidisciplinary treatment algorithm: a case series. Endoscopy 2011; 43: 160-2.

15 Keeling W B, Miller D L, Lam G T et al. Low mortality after treatment for esophageal perforation: a single-center experience. Ann Thorac Surg 2010; 90: 1669-73.

16 Makhani M, MIdani D, Goldberg A, Friedenberg F K. Pathogenesis and outcomes of traumatic injuries of the esophagus. Dis Esophagus 2014; 7: 630-6.

17 Ahmed N, Massier C, Tassie J, Whalen J, Chung R. Diagnosis or penetrating injuries of the pharynx and esophagus in the severely injured patient. J Trauma 2009; 67: 152-4.

18 Hardcastle T C. The spectrum, diagnosis and current management options of cervical, thoracic, and intra-abdominal esophageal perforations. J Trauma 2008; 65: 495.

19 Asensio J A, Chahwan S, Forno W et al. Penetrating esophageal injuries: a multicenter study of the American Association for the Surgery of Trauma. J Trauma 2001; 50: 289-96.

20 Freeman R K, Herrara A, Ascioti A J, Dake M, Mahidhara R S. A propensity-matched comparison of cost and outcomes after esophageal stent placement or primary surgical repair for iatrogenic esophageal perforation. J Thorac Cardiovasc Surg 2015; 149: $1550-5$

21 Sudarshan M, Elharram M, Spicer J, Mulder D, Ferri L E Management of esophageal perforation in the endoscopic era: is operative repair still relevant? Surgery 2016; 160: 1104-10.

22 Rinaldo B, Ronco C, Kellum J A, Mehta R L, Palevsky P. Acute renal failure - definition, outcome measures, animal models, fluid therapy, and information technology needs: the Second International Consensus Conference of the Acute Dialysis Quality Initiative Group. Crit Care 2004; 8: R204-12. (After 21)

23 Bone R C, Balk R A, Cerra F B et al. The ACCP/SCCM Consensus Conference Committee. American College of Chest Physicians/Society of Critical Care Medicine Definitions for sepsis and organ failure and guidelines for the use of innovative therapies in sepsis. Chest 1992; 101: 1644-55.

24 Nason K S. Is open surgery for iatrogenic esophageal perforation now a surgical relic, like bloodletting and trepanation? J Thorac Cardiovasc Surg 2015; 149: 1556-7.

25 Biffl W L, Moore E E, Feliciano D V et al. Western Trauma Association Critical Decisions in Trauma: diagnosis and management of esophageal injuries. J Trauma Acute Care Surg 2015; 79: 1089-95.

26 Ben-David K, Behrms K, Hochwald S et al. Esophageal perforation management using a multidisciplinary minimally invasive treatment algorithm. J Am Coll Surg 2014; 218: 768-74.

27 Markar S R, Mackenzie H, Wiggins T et al. Management and outcomes of esophageal perforation: A National Study of 2,564 patients in England. Am J Gastroenterol 2015; 110: $1559-66$. 